\title{
STRATEGI BRAIN BASED LEARNING DALAM PENGAJARAN BAHASA JEPANG DI MAN MOJOKERTO
}

\author{
Yulia Pratitis Yusuf \\ MAN Mojokerto, yulia_yusuf@ymail.com
}

\begin{abstract}
Japanese language teaching by lecture method used is irrelevant. It can be seen from the output of students who graduate high school, they generally have not been able to use the Japanese language in the context of natural communication. Japanese language learning should be done in harmony with the way the brain to learn something. It was due to the close links between the brain and language acquisition. Caine said there are twelve principles of brain work is the basis for the implementation of brain-based teaching. The twelve principles of brain functions must be implemented in three stages, namely the stage of teaching Japanese language to understand 「わかる」, remembering 「おぼえる」 and use 「つかう」. With Brain Based Learning troughout the student's potential can be optimally stimulated to learn Japanese. And when the twelve principles of brain functions in learning something can be understood by Japanese teachers well, then learning Japanese would be effective, enjoyable, meaningful and the most importantly, both Brain's hemispheres students can alsao develop optimally.
\end{abstract}

Keywords:Brain and Language, 12 principles of Brain system , BBL impact for students

\section{PENDAHULUAN}

Hasil dari pembelajaran bahasa asing di Indonesia sangat memprihatinkan. Hal itu dapat dilihat dari output pembelajaran bahasa Inggris. Pelajaran bahasa Inggris dipelajari siswa mulai dari SD hingga SMU. Idealnya, selama 12 tahun mempelajari bahasa Inggris, siswa akan mempunyai skills bahasa Inggris yang bagus. Tetapi pada kenyataannya siswa lulusan SMU tidak bisa menggunakan bahasa Inggris dalam konteks komunikasi sehari-hari dengan baik. Keadaan tersebut tidak berbeda dengan output yang dihasilkan pembelajaran bahasa Jepang di Indonesia. Dalam penjelasan kurikulum bahasa Jepang tahun 2006 disebutkan 
bahwa hasil pembelajaran Bahasa Jepang di Indonesia masih jauh dari tujuan yang diinginkan. Lulusan SMU belum mampu menggunakan bahasa Jepang dalam konteks komunikasi lisan dengan baik, inilah sesungguhnya permasalahan nyata dalam pengajaran bahasa Jepang di Indonesia yang harus segera dicarikan solusinya.

Saat ini yang terjadi adalah pengajaran bahasa asing (apapun bahasa asingnya termasuk bahasa Jepang) hanyalah sekedar transfer ilmu dari guru kepada siswanya, guru juga bukanlah seseorang yang mahatahu dan murid bukanlah yang belum tahu. Dalam proses belajar murid hendaknya aktif mencari tahu dengan membentuk pengetahuannya sendiri dan membiarkannya berfikir sendiri (Suparno, 1997:71).

Pengajaran bahasa saat ini sering menempatkan siswa pada situasi "diam”, yang menghambat kreativitas dan kemampuan siswa karena komunikasi pembelajaran hanya didominasi oleh guru saja (teacher centered) tanpa melibatkan peran aktif dari siswa. Pada saat proses pembelajaran berlangsung, hakekatnya guru tidak dihadapkan pada benda mati, melainkan mereka tengah menghadapi makhluk-makhluk yang unik, yang mempunyai kombinasi luar biasa antara talent (bakat), competance(kemampuan), and brain (otak).

Keistimewaan manusia bila dibandingkan dengan makhluk lainnya adalah terletak pada otak dan kemampuannya dalam berfikir. Sehingga sangat disayangkan bila kemampuan otak untuk berfikir tidak dioptimalkan. Sekolah sebagai lembaga pendidikan formal hendaknya menjadi suatu wadah yang bisa mengoptimalkan kemampuan otak dalam berfikir, dan memperhatikan fakta tentang pentingnya penggunaan otak dalam proses pembelajaran.

Guru bahasa asing haruslah memahami adanya keterkaitan antara neurologis siswa (dalam hal ini otak) dan pembelajaran bahasa. Bahkan Brown (2007:62) menjelaskan bahwa perkembangan neurologis sangat mempengaruhi pemerolehan bahasa kedua. Inilah mengapa guru bahasa asing apapun, termasuk 
guru bahasa Jepang juga harus memahami fungsi dan sistem kerja otak dalam pembelajaran.

Penelitian tentang pembelajaran dengan berbasis otak telah dilakukan oleh Judi Lombardi tahun 2004 tentang SLA (Second Language Acquisition research) yang hasilnya dimuat dalamThe Internet TESL Journal, sedangkan di Indonesia penelitian serupa telah dilakukan oleh Efendi dalam pembelajaran bahasa Inggris yang hasilnya diunggah dalam http://www.infodiknas.com/ dan Sapa'at dalam penelitian dalam bidang matematika yang hasilnya telah diunggah dalam http://matematika.upi.edu. Ketiga penelitian tersebut mempunyai kesimpulan yang sama bahwa cara siswa belajar yang paling efektif adalah dilakukan sesuai dengan cara kerja otak dalam mempelajari sesuatu.

Sebelum membicarakan tentang bagaimana otak manusia bekerja, sebaiknya kita memahami terlebih dahulu tentang bagian-bagian otak beserta fungsi-fungsinya.

Berikut ini adalah gambar penampang otak beserta bagian-bagiannya.
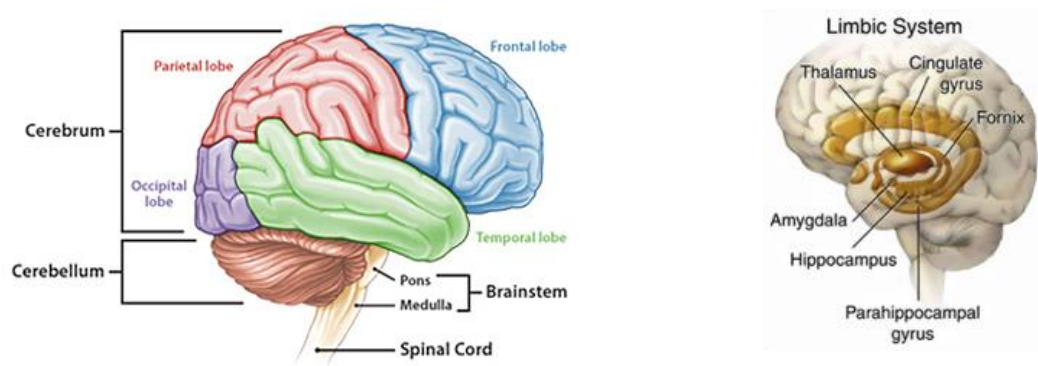

Gambar 1.

bagian-bagian Otak (Buzan:2009)

Dari gambar di atas, dapat diketahui bahwa otak manusia terdiri dari 4 bagian. Buzan (2009:30), menjelaskan fungsi masing-masing bagian tersebut, yaitu

1. Cerrebum atau otak Besar.

Otak besar dibagi menjadi 2 bagian, yaitu: 
Hemisfer kiri, bagian ini berfungsi untuk mengontrol sisi kanan tubuh. Otak kiri berfungsi dalam hal-hal yang berhubungan dengan logika, rasio, kemampuan menulis dan membaca, serta merupakan pusat matematika. Hemisfer kanan, bagian ini berfungsi untuk mengontrol sisi kiri tubuh, dan perkembangan Emotional Quotient (EQ). Misalnya sosialisasi, komunikasi, interaksi serta pengendalian emosi. Pada otak kanan ini juga terletak kemampuan intuitif, kemampuan merasakan, memadukan, dan ekspresi tubuh, seperti menyanyi, menari, melukis dan segala jenis kegiatan kreatif lainnya.

Di bawah ini adalah gambar fungsi hemisfer kiri dan kanan manusia.

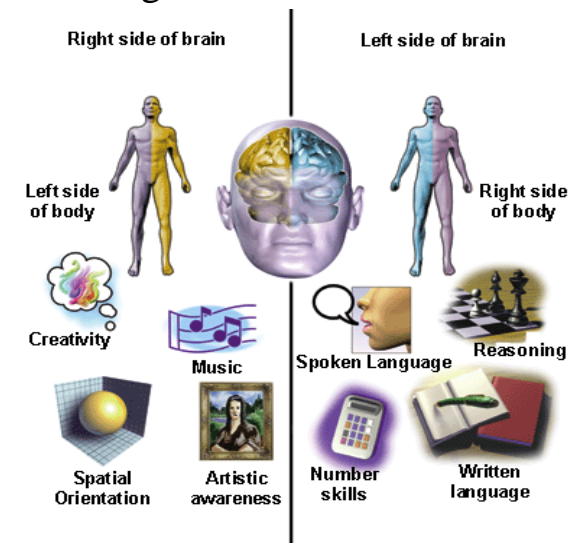

Gambar 2.

Ilustrasi Fungsi Otak Kanan \& Otak Kiri (Buzan:2009)

Dari gambar di atas dapat disimpulkan bahwa hemisfer kiri merupakan pengendali motorik tubuh bagian kanan dan menjadi pusat kegiatan akademik, bahasa dan kemampuan matematic manusia. Sedangkan hemisfer kanan merupakan pengendali motorik tubuh bagian kiri dan menjadi pusat intuitif, art dan kemampuan kreatif manusia yang $\underline{\text { lain. }}$ 
2. Cerrebelum (Otak kecil atau belakang), berfungsi untuk mengendalikan posisi tubuh, sikap tubuh dan keseimbangan, menyimpan ingatan untuk memberikan respon.

3. Brainstem (Batang Otak, Otak reptilian, Otak primitif), fungsinya adalah sebagai penyangga kehidupan dasar. Menangani pernapasan dan laju denyut jantung. Mengontrol tingkat kesiagaan, mengendalikan suhu, pencernaan, dan menjadi penerus informasi dari cerebellum.

4. Limbic System (Sistem Limbik, Otak mamalia, Otak tengah), bagian ini sangat penting bagi pembelajaran dan ingatan, menyimpan ingatan dari pengalaman hidup, dan terlibat dalam pengadaan emosi dan hasrat seksual.

Menurut kajian Neurolinguistik, pusat kecakapan (tata bahasa Linguistik) berada dalam tubuh manusia itu sendiri, yaitu di dalam korteks belahan sebelah kiri otak manusia yang berupa Wernicke's Area dan Medan Broca yang berada di dalam Girus Angular (Simanjuntak, 1990:56).

Broca dalam Simanjuntak, mengajukan 3 rumusan mengenai hubungan antara otak dan bahasa, yaitu "1) artikulasi bahasa diproses di konvolusi depan ke tiga hemisfer kiri otak, 2) terdapat dominasi hemisfer kiri dalam artikulasi bahasa ; 3) memahami bahasa merupakan tugas kognitif yang berlainan dari memproduksi bahasa”(1990: 192).

Manusia pada umumnya tidak pernah menyadari begitu rumitnya proses bahasa dalam otak. Sebagai guru bahasa kita harus memahami bagaimana proses bahasa dalam otak manusia. Hal ini penting untuk menjadi dasar pemilihan metode pengajaran bahasa yang sesuai dengan sistem kerja dan fungsi indra manusia.

Seiring dengan berkembangnya ilmu pengetahuan, guru bahasa Jepang hendaknya melakukan pembelajaran inovatif yang berbasis otak atau yang dikenal juga dengan istilah Brain Based Learning, agar pembelajaran bisa dilakukan dengan efektif sehingga menghasilkan output yang sesuai dengan tujuan 
pembelajaran bahasa, dan pada akhirnya akan membawa siswa pada kemampuan penggunaan bahasa Jepang dalam konteks komunikasi alamiah sehari-hari.

\section{PEMBAHASAN}

Brain Based Learning

Brain Based Learning hadir setelah Paul Mc Clean memaparkan hipotesis terkenalnya tentang revolusi otak, yaitu Triune Theory yang mengulas tentang anatomi otak dan fungsinya pada tahun 1970. Hal senada juga diungkapkan oleh Eric Jansen (2008:40) yang mengungkapkan bahwa ketika kita belajar untuk mengajar dengan cara yang alami bagi otak, akan sangat membantu jika kita mempunyai pemahaman akan otak.

Teori Paul Mc Clean dan Eric Jansen inilah yang membawa perubahan dalam dunia pendidikan terutama sebagai dasar dalam pengembangan strategi pembelajaran yang berbasis Otak sehingga seluruh potensi siswa dapat dirangsang secara optimal untuk belajar.

Pembelajaran dengan menggunakan pendekatan Brain Based Learning (Jensen, 2008: 12) adalah pembelajaran yang didesain dan diselaraskan dengan cara otak untuk belajar secara alamiah. Dalam pelaksanaan Brain Based learning menurut Caine dalam Lombardi (2004 dalam The Internet TESL Journal yang diunggah dalam http://http://iteslj.org/) menyebutkan bahwa ada 12 prinsip kerja Otak yang menjadi dasar dalam pelaksanaan pengajaran yang berbasis Otak, yaitu 1. The Brain is a Complex Adaptive System, Otak merupakan pusat dari berbagai aktivitas manusia, menggabungkan emosi, imajinasi untuk memproses informasi dalam satu waktu secara bersamaan.

2. The Brain is a Social Brain, Otak manusia pada prinsipnya senang pada kegiatan yang dilakukan dalam interaksi sosial atau kelompok. 
3. The Search for Meaning is Innate, Otak menyukai akan penjelasan dan pemahaman akan makna sesuatu yang dipelajarinya.

4. The Search for Meaning Occurs Through Patterning, maksudnya adalah Otak pada waktu melakukan pencarian makna dengan cara meniru.

5. Emotions Are Critical to Patterning, menurut psikolog John Mayer dan Peter Saloveymenyatakan bahwa orang yang memiliki Emotional Intellegence (EQ) akan lebih sukses daripada orang yang memiliki indeks IQ yang tinggi. Hal itu dikarenakan, manusia dengan EQ yang tinggi memiliki rasa optimis yang tinggi pula.

6. Every Brain Simultaneously Perceives and Creates Parts and Wholes. Otak belahan kanan dan kiri manusia mempunyai fungsinya masing masing. Walaupun memiliki fungsi yang berbeda, namun kedua otak ini berinteraksi dalam semua aktifitas.

7. Learning Involves Both Focused Attention and Peripheral Perception. Pada saat belajar, otak melibatkan perhatian yang fokus dan persepsi yang meluas. Otak menyerap informasi yang diterima secara langsung dan menyerap informasi yang terjadi di luar fokus perhatian.

8. Learning Always Involves Both Conscious and Unconscious Processes, maksudnya belajar selalu melibatkan proses sadar dan tidak sadar.

9. We Have at Least Two Ways of Organizing Memory, maksudnya kita memiliki setidaknya dua sistem memori, yaitu spasial dan hafalan. Sistem memori spasial atau memori otobiografi alamiah yang kita miliki merekam semua yang terjadi pada tubuh. Kita juga memiliki system hafalan yang merecall informasi. Sistem-sistem ini termotivasi oleh adanya reward dan hukuman.

10. Learning is Developmental, maksudnya otak manusia terdiri dari milyaran sel neuron yang tumbuh terus menerus sesuai dengan hal baru yang dipelajarinya.

104 | http://journal.unesa.ac.id/index.php/paramasastra 
11. Complex Learning Is Enhanced by Challenge and Inhibited by Threat, Otak dapat belajar secara optimal dan menciptakan koneksi maksimum saat menerima tantangan. Sebaliknya, otak menjadi tidak fleksibel dan kembali pada kelakuan primitif ketika di bawah ancaman.

12. Every Brain Is Uniquely Organized, artinya Setiap otak adalah unik. Kita semua memiliki sistem otak yang sama, namun secara keseluruhan daya berfikir, imajinatif dan kreatif kita berbeda.

Ke dua belas prinsip dasar kerja Otak di atas merupakan prinsip yang harus diperhatikan dalam pelaksanaan Brain Based Learning agar guru bisa menyusun strategi pengajaran yang sesuai atau selaras dengan cara otak mempelajari sesuatu.

\section{Pembelajaran Bahasa Jepang}

Dalam kurikulum tahun 2006 dijelaskan bahwa mata pelajaran bahasa Jepang merupakan mata pelajaran pilihan di SMA/MA, salah satu tujuan pembelajaran bahasa Jepang adalah untuk mengembangkan kemampuan siswa dalam hal berbicara, mendengarkan, membaca, berbicara, dan menulis dalam bahasa Jepang secara baik.

Empat kemampuan berbahasa tersebut bisa dicapai dalam pembelajaran bahasa Jepang bila pada saat belajar, mereka mendapatkan rangsangan dan metode pembelajaran yang tepat dari gurunya.

Dalam pengajaran bahasa Jepang ada urutan pembelajaran yang harus dilakukan oleh guru, agar siswa mudah memahami bahasa Jepang. Pada saat mempelajari kosakata baru bahasa Jepang sampai dapat menggunakannya, pada umumnya menempuh tahapan sebagai berikut (Kojimatsu, 2012)

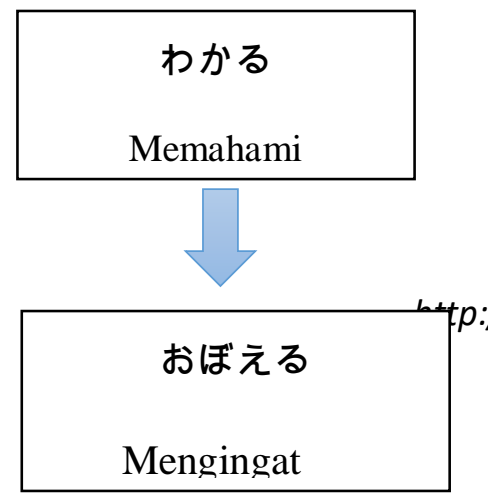

Memahami arti kata dan pola kalimat 


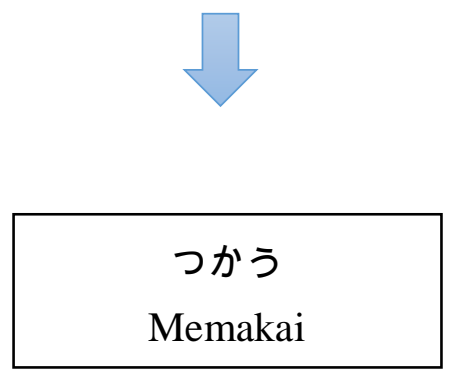

Menggunakan dengan lancar kata dan pola kalimat dalam situasi sebenarnya.

Bagan. 1 Diagram Tahap Pembelajaran bahasa Jepang

Tahap pembelajaran bahasa Jepang menurut Koji Matsumoto (2013) ada tiga, yaitu（1) Memahami (わかる) (2) Mengingat（おぼえる)，dan (3) Menggunakan (つかう). Pada tahap (1) dan (2) yang berperan dominan adalah aspek kognitif siswa, dimana aspek kognitif sangat dipengaruhi oleh system kerja otak bagian kiri.

Sedangkan tahap ke-3 merupakan latihan penggunaan dari apa yang telah dipahami dan diingat dalam suatu tuturan lengkap. Pada tahap ke-3 yaitu tahap Menggunakan (つかう) bahasa Jepang yang telah dipelajari, siswa tidak hanya dipengaruhi oleh system kerja otak bagian kiri saja, melainkan juga melibatkan otak kanan dan dukungan indrawi lainnya.

Penerapan Prinsip Brain Based Learning dalam Pembelajaran bahasa Jepang di MAN MOJOKERTO

Pembelajaran bahasa Jepang dapat berlangsung dengan efektif, dan siswa mampu menguasai 4 ketrampilan dasar berbahasa, bila guru bahasa Jepang mau meninggalkan metode konvensional dalam mengajar dan beralih menggunakan pendekatan pembelajaran berbasis otak.

106 | http://journal.unesa.ac.id/index.php/paramasastra 
Dengan pembelajaran yang berbasis otak seluruh potensi siswa dapat dirangsang secara optimal untuk belajar bahasa Jepang.

Berikut ini adalah penerapan prinsip-prinsip Brain Based Learning dalam pembelajaran bahasa Jepang di MAN MOJOKERTO, yaitu:

1. Dikarenakan otak merupakan system yang kompleks, maka pada saat memberikan tugas pada siswa, guru bahasa Jepang harus kreatif, dengan memberikan tugas yang merangsang semua bagian otak untuk bekerja. Misalnya pada saat mempelajari tema “Uchi (rumah)”, guru bisa memberikan tugas pada siswa untuk menceritakan situasi kamarnya dengan menunjukkan gambar kondisi kamar masing-masing dan menceritakannya di depan kelas, sehingga kemampuan bahasa, dan imajinatif serta kreasi mereka dirangsang secara bersamaan.

2. Otak pada dasarnya menyukai kegiatan yang dilakukan secara kelompok. Maka strategi pembelajaran bahasa Jepang yang tepat adalah dengan Cooperative Learning. Dalam pembelajaran bahasa Jepang banyak sekali kegiatan yang bisa dilakukan dalam kelompok, yaitu Interview (インタビュー), Role Play (ロールプレー), Game (ゲーム), Information Gap (インフォメーションギャップ), dan Pair/berpasangan (ペアペア). Kegiatan kelompok ini juga bermanfaat meningkatkan rasa percaya diri siswa

Berikut ini adalah contoh kegiatan yang dilakukan secara berkelompok:
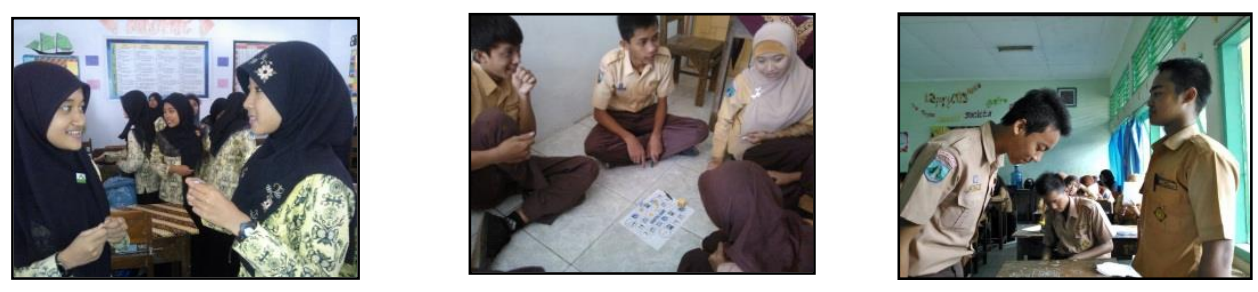
Gambar 3 . Interview

Gambar 4. Game

Gambar

5.

Berpasangan

3. Karena Otak lebih menyukai "mengapa mempelajari sesuatu” daripada "apa dan bagaimana sesuatu dipelajari”, maka memahami tujuan pembelajaran dari tema yang akan dipelajari adalah penting. Guru bahasa Jepang pada tahap pengajaran nomer (1) yaitu tahap Memahami (わかる), haruslah menjelaskan pentingnya apa yang akan dipelajari, dan juga menjelaskan tujuan serta kegunaan tema yang akan dipelajari. Misalnya saat guru akan menjelaskan tema “Kazoku” (keluarga) dengan pola kalimat [〜は〜です] / [ wa desu], maka sebelum masuk ke materi, guru memberikan penjelasan tentang kegunaan mempelajari materi keluarga ini, yaitu agar siswa mampu bercerita tentang keluarga dan saudaranya dalam bahasa Jepang. Dengan memberikan pemahaman pada siswa, serta mengaitkannya dengan kehidupan nyata siswa, berarti guru telah memberikan motivasi dan menunjukkan keterpakaian dari materi baru yang akan dipelajari.

4. Pada saat mempelajari sesuatu yang baru, Otak mencari pengetahuan dan pengalaman dari apa yang dilihat atau diamati sebelumnya. Jadi pada saat akan memulai pelajaran atau memasuki tema baru dan pada saat melakukan Pengantar sebelum pembelajaran dimulai[授業の導入]/jyuugyou no donyuu, guru sebaiknya menggunakan media gambar, video, film, anime, boneka tangan, poster, foto dan sebagainya yang berhubungan dengan tema yang akan dipelajari untuk mempersiapkan otak siswa menerima pengetahuan baru dan menjadikan proses belajar lebih bermakna dan menyenangkan.

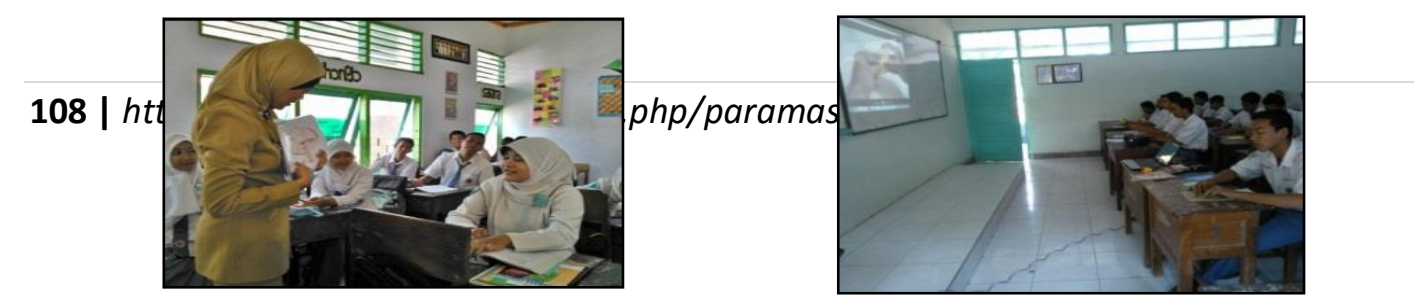



media video

5. Pada saat peniruan, (saat siswa menirukan kosakata dan kalimat yang diucapkan guru, dan pada saat siswa menirukan apa yang didengar atau dilihat dari kaset dan video) emosi sangat mempengaruhi sukses tidaknya peniruan tersebut. Sehingga guru bahasa Jepang, harus dapat menciptakan situasi belajar yang menyenangkan dan menggunakan strategi pembelajaran yang bervariasi untuk menjaga mood siswa dan agar pembelajaran bahasa Jepang tidak membosankan.

6. Pada saat berfikir, semua bagian otak, baik hemisfer kiri maupun hemisfer kanan bekerjasama secara sinergis. Karena itulah, pembelajaran bahasa Jepang harus menggunakan pendekatan lintas disiplin untuk mengaktifkan kedua belahan otak tersebut. Misalnya, pada saat mengajarkan perubahan kata kerja bentuk [ て形/ te kei], nama-nama hari dan lain sebagainya, guru menggunakan media nyanyian agar siswa mudah dan cepat hafal materi baru yang dipelajarinya.

Berikut ini adalah contoh lagu yang telah dimodifikasi untuk penyampaian materi pembelajaran

"Minna de Tanoshiku” (melodi yang digunakan adalah "Twinkle-twinkle Little Star")

$\begin{array}{llllllllllllll}1 & 1 & 5 & 5 & 6 & 6 & 5 & 4 & 4 & 3 & 3 & 2 & 2 & 1\end{array}$

Tatte suwatte hon o akete minna de tanoshiku hajimemashou Berdiri duduk buka buku mari kita mulai dengan gembira 
$\begin{array}{llll}5 & 5 & 4 & 4\end{array}$

Teepu o kite

Dengar tape

\section{$\begin{array}{lll}3 & 3 & 2\end{array}$}

e o mite

Lihat gambar

\section{$5 \quad 5 \quad 4$}

hon o yonde

baca buku

\section{$\begin{array}{lllll}4 & 3 & 3 & 2 & 2\end{array}$}

sakubun o kaite tulis karangan

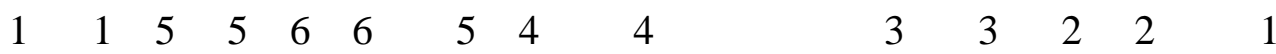

Tatte suwatte hon o akete minna de tanoshiku hajimemashou

Berdiri duduk buka buku mari kita mulai dengan gembira

(The Japan Foundation, "Sakura 1", 2009:6)

7. Sistem kerja otak dalam belajar adalah otak siswa tidak hanya memperhatikan materi utama yang tengah diajarkan, tetapi siswa juga memperhatikan hal-hal kecil lain yang kadang tidak diperhatikan oleh guru. Misalnya, pada saat guru memberikan contoh kalimat dalam bahasa Jepang, intonasi, aksen, mimic, dan gesture guru pada saat bicarapun tidak luput dari perhatian siswa. Siswa menganggap hal-hal tersebut juga harus ditiru persis, sama dengan yang dilakukan gurunya. Maka guru harus berhati-hatil pada saat memberikan contoh pada murid-muridnya.

8. Belajar melibatkan proses sadar dan bawah sadar. Belajar bukan hanya terjadi di dalam kelas, namun juga dalam kehidupan sehari-hari. Sebisa mungkin guru merangsang siswa untuk menggunakan apa yang telah dipelajarinya dalam percakapan sederhana sehari-hari, misalnya dengan mengucapkan salam menggunakan bahasa Jepang pada saat bertemu di luar kelas. Atau menggunakan percakapan sederhana lainnya yang telah dipelajari. Kegiatan atau aktivitas pembelajaran harus dititik beratkan pada fungsi bahasa itu sendiri, yaitu penggunaan. Karena itulah pada waktu melakukan kegiatan kelas pada tahap Aplikasi (Ouyo renshuu), dapat dilakukan dengan menghadirkan situasi seolah-olah nyata, misalnya dengan kegiatan Role play(bermain peran), Interview, Information gap atau game, juga bisa mengadakan pembelajaran outdoor class sesuai dengan tema yang tengah dipelajari. 
9. Pada tahap (2) yaitu Mengingat 「おぼえる」, guru bisa menggunakan system hafalan. Ada sebagian dari kita yang menganggap pembelajaran dengan sistem hafalan adalah "jelek", tetapi itu tidak seluruhnya benar (Nur, dkk. 2008). Kadang hafalan dalam upaya pemerolehan B2 merupakan cara cepat untuk mengingat sesuatu. Agar pembelajaran menjadi bermakna, dan siswa tidak merasa "tersiksa" saat menghafal, guru bisa menggunakan media kartu gambar untuk kosakata yang akan dihafalkan siswa. Mengajarkan kosakata baru dengan menggunakan media gambar akan mempermudah koordinasi antara mata, fikiran dan ingatan siswa. Kemudian, bila siswa sudah bisa mengingat atau menghafal dengan baik kosakata baru yang dipelajarinya, guru jangan lupa untuk memberikan reward berupa pujian untuk memotivasi dan meningkatkan rasa percaya diri siswa.

10. Mempelajari sesuatu yang baru sebenarnya membuat Otak dan kemampuan berfikir kita tumbuh, hal inilah yang harus diperhatikan oleh guru bahasa Jepang dengan selalu menggunakan strategi pembelajaran yang berbeda saat mengajar. Jangan menggunakan metode yang sama terus, karena siswa akan bosan, otaknya tidak berkembang dan mematikan daya kreasi mereka.

11. Belajar dapat ditingkatkan dengan memberikan tantangan, tetapi belajar juga bisa menjadi stagnan atau tidak berkembang bila siswa merasa mendapat ancaman. Guru bahasa Jepang harus tahu level kemampuan siswanya. Jangan sampai memberikan materi yang terlalu mudah, hal ini bisa membuat siswa malas belajar, karena merasa sudah bisa.Tetapi sebaiknya memberikan materi atau tugas yang sedikit lebih diatas kemampuan mereka, agar mereka tertantang. Misalnya, memberikan tugas membuat Poster 「ポスター」, membuat video dokumentasi kegiatan sehari-hari 「ビデオを作る」， 
pidato「スピーチ」, bercerita [発表] dan mengarang 「作文」dan sebagainya. Pada saat proses belajar mengajar guru juga tidak boleh meremehkan atau menghina siswa, karena siswa akan menjadi rendah diri dan tidak berani mencoba karena takut salah.
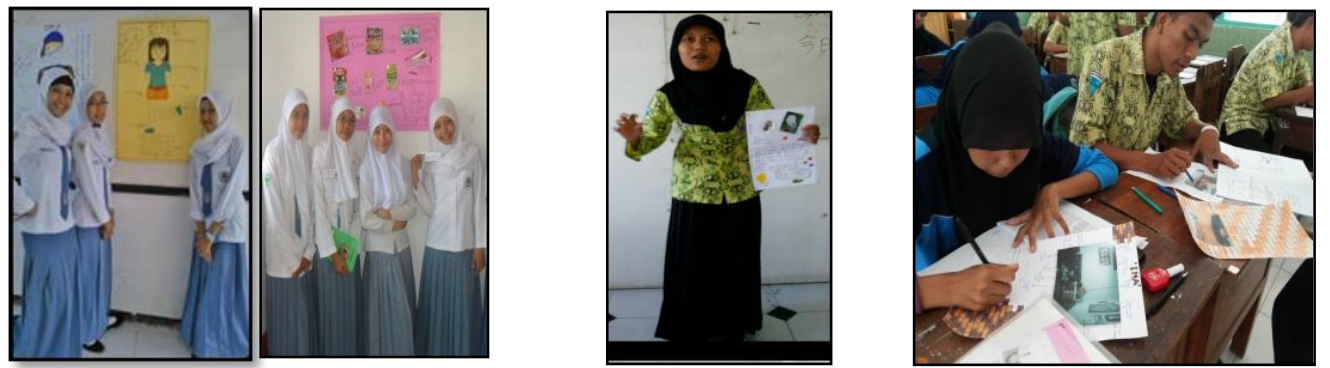

Gb. 8. Membuat Poster「「ポスター」Gb.9. Bercerita[発表] Gb.

\section{Mengarang 「作文」}

12. Masing-masing siswa kita adalah pribadi yang unik, tidak sama antara satu dengan yang lainnya. Karena itulah guru bahasa Jepang harus bisa membuat pembelajaran klasikal yang juga memperhatikan kebutuhan personal masingmasing individu. Tidak ada istilah siswa bodoh bila guru bisa menggunakan strategi dan pendekatan pembelajaran yang tepat untuk siswanya.

Berikut ini adalah table yang menunjukkan penerapan 12 prinsip kerja otak dalam pembelajaran bahasa Jepang di MAN MOJOKERTO dan efeknya pada siswa.

Tabel 1 Penerapan 12 prinsip Brain Based Learning dan efeknya bagi siswa.

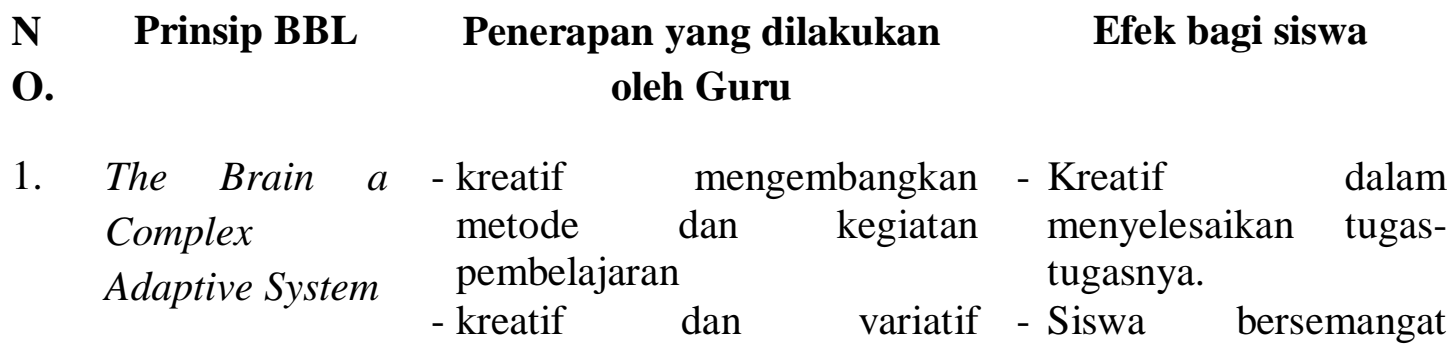

112 | http://journal.unesa.ac.id/index.php/paramasastra 
memberikan tugas portofolio yang menantang bagi siswa

- kreatif menciptakan berbagai media pengajaran.

2. The Brain is a - Menerapkan cooperative Social Brain learning. Misalnya kegiatan Interview, Game, Role play, Information gap dll

- Membentuk kelompok siswa

3. The Search for Meaning is Innate

\section{- Menjelaskan} tujuan maksud pembelajaran jelas yang heterogen.
- Mengaitkan pembelajaran kehidupan sehari-hari siswa.

- Memotivasi siswa

4. The Search for Meaning Occurs Through Patterning

Critical to

Patterning
5. Emotions Are-Menerapkan Joy learning

dalam menyelesaikan tugas-tugas

- Dapat bersosialisasi dengan teman

-Dapat bekerjasama dalam kelompok

-Percaya diri

Memahami dengan jelas tujuan pembelajaran

- Bisa memakai dari apa yang telah dipelajari dalam komunikasi sederhana sehari-hari

- termotivasi dalam belajar bahasa Jepang

- Menggunakan media yang - siswa mempunyai variatif sesuai dengan materi. imajinasi tinggi Misalnya boneka tangan, foto, - kosakata baru lebih poster, video, gambar, film, cepat dihafal dan anime, manga dll. dipahami

- Tidak bosan belajar bahasa Jepang

- Muncul sikap optimis mampu menguasai bahasa Jepang dengan baik

- senang belajar bahasa Jepang

6. Every Brain - Menggunakan berbagai - Otak kanan dan kiri Simultaneously macam metode dalam sinergis dan balance.

Perceives and pengajaran - Lebih mudah Creates Parts Misalnya, menggunakan media menghafal dan and Wholes. lagu untuk menerangkan kosa kata baru, atau materi yang sulit mengerti materi baru.

- belajar bahasa Jepang lebih menyenangkan 
7. Learning

Involves

Focused

Attention and

Peripheral

Perception.
- Memberikan contoh yang tepat dalam pelafalan, intonasi dan gesture.
- Tepat dalam peniruan, sehingga meminimalisir kesalahan.
8. Learning
- Melakukan

$$
\text { pembelajaran }
$$
outdoor class.

Always Involves

Both Conscious

and

Unconscious

Processes
- Menghadirkan

situasi「場面」yang

mendekati nyata

- Membiasakan menggunakan percakapan sederhana dengan siswa di luar kelas
- Materi akan lebih mudah dipahami, karena siswa ada pada situasi yang mendekati alami.

- Terbiasa mendengarkan kata2 bahasa Jepang sehingga tidak gampang lupa

- Bisa menggunakan percakapan yang dipelajari di dalam kelas dalam situasi real.

9. We Have at - Guru tidak tabu menggunakan

- Menghafal kosakata Least Two Ways of Organizing Memory tekhnik hafalan dalam pembelajaran B2

- Hafalan dilakukan tetap dalam situasi joy learning, yaitu dengan bantuan kartu, gambar, game dll.

- Memberikan reward

- Memberikan punishman yang mendidik

10. Learning is - Tidak menggunakan metode Developmental

pengajaran yang sama terus
menerus
- Menggunakan metode yang
bervariasi dalam
menyampaikan materi baru

11. Complex

- Mengetahui level kemampuan

Learning masing-masing siswanya.

Enhanced baru bahasa Jepang dengan semangat, karena ada reward bila berhasil.

- Menghafal dengan menyenangkan, tidak menyadari bahwa mereka sedang melakukan hafalan

- Daya kreatif, imajinatif dan intuitif siswa berkembang dengan baik - siswa tidak bosan dengan pelajaran bahasa Jepang

- Merasa tertantang untuk menyelesaikan tugas dengan baik

- Belajar bahasa Jepang

114 | http://journal.unesa.ac.id/index.php/paramasastra 


$\begin{array}{lrll}\text { Challenge and } & \text { siswa sehingga menjadi } & \text { dengan rajin } \\ \text { Inhibited } & \text { by } & \text { tantangan bagi mereka } & \text { - Terciptanya suasana } \\ \text { Threat } & \text { - Tidak menghina atau } & \text { kompetisi antar siswa } \\ & \text { mengancam siswa bila siswa } & \text { yang sehat. } \\ & \text { tidak bisa } & \text { - Siswa belajar dengan } \\ & & \text { tenang karena tidak } \\ & \text { merasa dalam tekanan }\end{array}$

12. Every Brain Is - Menyadari bahwa kecepatan - Mendapatkan perhatian Uniquely dan cara belajar antar siswa yang sama dari Organized

tidak sama
- Menciptakan design
pembelajaran yang efektif dan
mencakup kebutuhan semua
siswa
- Melakukan pendekatan yang
berbeda bagi siswa-siswa yang
lambat belajar atau
mempunyai sikap negative
misalnya siswa malas, nakal
dll

\section{gurunya.}

- Merasa menjadi siswa yang special karena perlakuan yang diterima dari gurunya tidak sama dengan temannya, sehingga menjadi motivasi .

- Bisa mencapai

ketrampilan bahasa Jepang dengan baik.

Dalam penerapan 12 prinsip kerja otak dalam pembelajaran bahasa Jepang, guru harus memperhatikan 3 strategi pembelajaran, yaitu (1) menciptakan lingkungan belajar yang menantang kemampuan berpikir siswa; (2) menciptakan lingkungan pembelajaran yang menyenangkan, dan (3) menciptakan situasi pembelajaran yang aktif dan bermakna bagi siswa (Sapa'at:2009 dalam http://matematika.upi.edu/).

Sehubungan dengan implementasi Brain Based learning dalam pembelajaran, guru bahasa Jepang bisa mengembangkan proses belajar mengajarnya dengan pendekatan PAIKEM. PAIKEM merupakan akronim dari Pembelajaran Aktif, Inovatif, Kreatif, Efektif dan Menyenangkan (Fachrurrozi :2010). Dengan menggunakan PAIKEM diharapkan pembelajaran bahasa Jepang bisa lebih efektif dan bermakna serta selaras dengan prinsip kerja otak siswa dalam belajar, sehingga tujuan pembelajaran bahasa Jepang yaitu agar siswa 
menguasai 4 ketrampilan bahasa dapat tercapai dan bisa menggunakan bahasa Jepang dalam konteks komunikasi nyata dalam kehidupan sehari-hari.

\section{SIMPULAN}

Pengajaran bahasa Jepang yang efektif, inovatif dan menyenangkan harus memperhatikan dan selaras dengan 12 prinsip dasar kerja otak manusia. Kedua belas prinsip kerja otak dalam mempelajari sesuatu itu adalah The Brain $a$ Complex Adaptive System, The Brain is a Social Brain, The Search for Meaning is Innate, The Search for Meaning Occurs Through Patterning, Emotions Are Critical to Patterning, Every Brain Simultaneously Perceives and Creates Parts and Wholes, Learning Involves Both Focused Attention and Peripheral Perception, Learning Always Involves Both Conscious and Unconscious Processes, We Have at Least Two Ways of Organizing Memory, Learning is Developmental, Complex Learning Is Enhanced by Challenge and Inhibited by Threat, dan Every Brain Is Uniquely Organized.

Pembelajaran bahasa Jepang bila dilakukan dengan menyelaraskan 12 prinsip dasar kerja otak berarti guru tidak hanya mengasah kemampuan kognitif siswa saja, tetapi juga telah mengembangkan kreatifitas, rasa percaya diri, kemampuan berinteraksi kelompok dan sekaligus juga memotivasi siswa untuk belajar bahasa Jepang dan menggunakan apa yang telah dipelajari dalam percakapan alamiah sehari-hari.

Pembelajaran bahasa Jepang dengan berbasis otak harus memfasilitasi kebutuhan siswa untuk bersosialisasi dengan temannya melalui berbagai macam kegiatan pembelajaran misalnya Interview (インタビュー), Role Play
(ロールプレー), Game
$($ ゲーム),
Information
Gap
(インフォメーションギャップ), dan Pair/berpasangan (ペアペア). 
Menempatkan siswa sebagai centered dalam pembelajaran, memberikan reward dan punishman yang mendidik, memperhatikan emosi atau kejiwaan siswa dengan menciptakan suasana belajar yang menyenangkan dan menggunakan berbagai metode dan media yang bervariatif agar pembelajaran bahasa Jepang tidak monoton dan membosankan. Selain itu, dengan menggunakan Brain Based Learning dalam pembelajaran bahasa Jepang, seluruh potensi siswa dapat berkembang secara optimal.

Pengajaran bahasa Jepang yang baik adalah pengajaran yang dilakukan selaras dengan 12 prinsip kerja otak manusia. Pembelajaran konvensional dengan metode ceramah dan teacher centered sudah tidak relevan lagi digunakan. Maka guru bahasa Jepang saat ini hendaknya menerapkan Brain Based Learning dalam pengajaran bahasa Jepang. Hal ini perlu dilakukan, agar pembelajaran bahasa Jepang semakin bermakna, dan siswa bisa menguasai 4 kemampuan berbahasa yaitu membaca, menulis dan mendengar dengan baik.

\section{Daftar Pustaka}

Brown, H. Douglas. 2007. Prinsip Pengajaran dan Pembelajaran Bahasa, Edisi Kelima Terjemahan. Jakarta: Kedutaan Besar Amerika Serikat Jakarta.

Buzan, Tony, 2009. Buku Pintar Mind Map. Jakarta: Gramedia.

Efendi, 2013 “Brain Based Learning dalam pembelajaran bahasa Asing”dalam http://www.infodiknas.com/ yang diakses pada tanggal 4 Juni 2013.

Fachrurrozi. 2010. Pembelajaran Bahasa Asing. Jakarta: Bania Publishing.

Jensen, E. 2008. Pembelajaran Berbasis Kemampuan Otak: Cara Baru dalam Pengajaran dan Pelatihan. Yogyakarta: Pustaka Pelajar.

Koji, Matsumoto. 2012."PAIKEM ni tsuite Kagaeyou" dalam http://www.kojimatsu.com/UNESAS2201213A/Home.htmlyang diakses pada tanggal 4 Juni 2013. 
Lombardi. 2004 "Practical Ways Brain Ways Brain-based Research Applies to ESL Learners" dalam The Internet TESL Journal For Teachers of English as a Second Language, http://http://iteslj.org/yang diakses tanggal 4 Juni 2013.

Nur, Mohammad, dkk. 2008. Teori-Teori Pembelajaran Kognitif. Surabaya: UNESA Pusat Sains dan Matematika Sekolah.

Sapa'at, A. 2009 "Brain Based Learning", dalam http://matematika.upi.edu/, yang diakses pada 4 Juni 2013.

Simanjuntak, Mangantar. 1990. Teori Linguistik Chomsky dan Teori Neurolinguistik Wernicke. Jakarta: Gaya Media Pratama.

Suparno, Paul. 1997. Filsafat kontruktivisme dalam Pendidikan. Yogyakarta: Kanisius.

Syafa'at. 2007. "Brain Based Learning”, dalam http://sahabatguru.wordpress.com/2007, yang diakses tanggal 4 Juni 2013.

Tim. 2007. Buku Pelajaran Bahasa Jepang 1 にほんご. Jakarta: The Japan Foundation- Direktorat Pembinaan SMA DITJEN Manajemen DIKDASMEN Kementrian Pendidikan Nasional RI. 